\title{
Larval Dispersal and Predation in Experimental Populations of Chrysomya albiceps and Cochliomyia macellaria (Diptera: Calliphoridae)
}

\author{
Juliana Bartholo de Andrade, Fabrícia Aparecida Rocha*, Patrícia Rodrigues, Gisele Souza \\ Rosa, Lucas Del Bianco Faria, Cláudio José Von Zuben**, Marcelo Nogueira Rossi, \\ Wesley Augusto Conde Godoy/ ${ }^{+}$
}

\author{
Departamento de Parasitologia, Instituto de Biociências *Faculdade de Medicina Veterinária e Zootecnia, Universidade \\ Estadual Paulista, 18618-000 Botucatu, SP, Brasil **Departamento de Zoologia, Instituto de Biociências, \\ Universidade Estadual Paulista, Rio Claro, SP, Brasil
}

In this study we investigated the larval dispersal associated with larval predation in experimental populations of Chrysomya albiceps and Cochliomyia macellaria. Frequency distribution of sampling units (G test) in the substrate was used to evaluate variation in larval dispersal. An experimental acrylic channel $\left(\begin{array}{lllll}1 & 0.1 & 0 & 0.2 & m\end{array}\right)$ covered with wood shavings was used to observe larval dispersal prior to pupation. The acrylic channel was graduated at $0.05 \mathrm{~m}$ intervals, each representing a sampling unit; hence, 20 sampling units were set up. A Petri dish containing third instar larvae of single and double species was deposited at one edge of the acrylic channel allowing larvae to disperse. The number of buried pupae $(0,1,2, \ldots n)$ present in each sampling unit was recorded. For double species, the number of recovered larvae of $\mathrm{C}$. albiceps was similar to the number initially released on the dish Petri. On the other hand, the number of recovered larvae of C. macellaria was significantly smaller than the initially released number. The results show that $\mathrm{C}$. albiceps attacks $\mathrm{C}$. macellaria larvae during the larval dispersal process. The larval distribution of C. albiceps did not differ significantly from $\mathrm{C}$. macellaria in double species, but it differed significantly in single species. The larval aggregation level of $\mathrm{C}$. macellaria decreased when $\mathrm{C}$. albiceps was present and the larval aggregation level of $\mathrm{C}$. albiceps increased when $\mathrm{C}$. macellaria was present. The implications of such findings for the population dynamics of these species are discussed.

Key words: larval dispersal - predation - frequency distribution - blowflies

Larval dispersal is an important process in the life cycle of blowflies since during this period larvae leave their food substrate looking for a suitable place to bury and pupate (Levot et al. 1979). During this phase, the blowfly larvae may be at risk of predation, parasitation and desiccation (Legner 1977, Peschke et al. 1987). In two previous studies, Godoy et al. (1995, 1996) investigated the dispersal of post-feeding larvae of Chrysomya megacephala (Fabricius), C. putoria (Wiedemann) and Cochliomyia macellaria (Fabricius). They found that most larvae of $C$. megacephala, C. putoria and C. macellaria pupated close to the food source, although the maximum distance traveled by the larvae differed among the three species, with $C$. megacephala and $C$. putoria larvae reaching a greater maximum dispersal distance than $C$. macellaria.

Statistical analysis of the frequency distribution of dispersing blowfly larvae revealed that aggregated patterns of distribution emerge as a consequence of dispersal,

LDBF and MNR have been supported by research fellowships from Fapesp (01/13920-3, 01/06368-2); GSR and CJVZ have been supported by research fellowships from Capes and CNPq, respectively.

${ }^{+}$Corresponding author. Fax: + 55-14-821.3744. E-mail: wgodoy@ibb.unesp.br

Received 7 May 2002

Accepted 26 August 2002 and $C$. macellaria has higher aggregation levels than $C$. megacephala and C. putoria (Godoy et al. 1996). Thus, aggregated patterns of distribution during the larval dispersal process may have important implications for the ecology of these species. Predation of post-feeding larvae by Coleoptera and attack by parasitoids occur primarily in the neighborhood of the food source (Peschke et al. 1987) and can also contribute in reducing fitness. It has been estimated that predation and parasitation during pre-adult stages, mainly pre-pupae and pupae, can raise mortality rates up to $60 \%$ in some blowfly species (Putman 1977).

Chrysomya albiceps (Wiedemann) is a facultative predator of other dipteran larvae (Fuller 1934, Coe 1978, Gagné 1981, Erzinçlioglu \& Whitcombe 1983) and this habit probably has important effects on such prey species, particularly in communities where reduction in population size of native species is evident (Hanski 1977, Goodbrod \& Goff 1990, Wells \& Greenberg 1992a,b,c). Recently, Faria et al. (1999) and Faria and Godoy (2001) investigated facultative predation rates on third instar larvae of $C$. macellaria, C. putoria and C. megacephala by third instar larvae of $C$. albiceps in no-choice, two-choice and three-choice situations. The highest predation rate occurred for $C$. macellaria larvae, suggesting that $C$. albiceps has a higher predation impact on $C$. macellaria than the other prey species.

Although several studies regarding population interactions between the introduced species $C$. albiceps, $C$. 
rufifacies (Macquart), C. putoria and C. megacephala, and the native species $C$. macellaria have been carried out (Wells \& Greenberg 1992a,b,c, Faria et al. 1999, Reis et al. 1999, Faria \& Godoy 2001), no systematic study associating blowfly larval predation and dispersal is available in the literature. Here, we investigated the larval aggregation patterns of $C$. albiceps and C. macellaria in single and double species experiments in order to evaluate the possible associations between predation and dispersal.

\section{MATERIALS AND METHODS}

Laboratory studies - Newly hatched larvae of $C$. albiceps and C. macellaria were obtained from adult flies kept at constant temperature $\left(25^{\circ} \mathrm{C}\right)$ and $80 \%$ relative humidity, and raised in vials containing $50 \mathrm{~g}$ of ground beef. An experimental acrylic channel $(1 \mathrm{~m}$ long, $10 \mathrm{~cm}$ high, and $20 \mathrm{~cm}$ wide) covered with wood shavings was used to observe larval dispersal prior to pupation. The acrylic channel was graduated at $0.05 \mathrm{~m}$ intervals, each representing a sampling unit; hence, 20 sampling units were set up. A Petri dish containing third instar larvae of single and double species was deposited at one edge of the acrylic channel allowing larvae to disperse. The number of found pupae $(0,1,2, \ldots$ n) present in each sampling unit was recorded and plotted against its relative distance from the initial releasing point to assess the larval distribution pattern of each species. Two replicates per species were run, with 120 and 60 larvae in each replicate for single $C$. albiceps (120) and $C$. macellaria (120) and double $C$. albiceps (60) and C. macellaria (60) species, respectively.

Statistical analysis - Differences in larval dispersal patterns of postfeeding larvae between single and double blowfly species were evaluated by the $G$ test (Sokal \& Rohlf 1981). The frequency distribution of $C$. albiceps and C. macellaria pupae was fitted to the negative binomial distribution in order to determine whether larval dispersal was aggregated. The $k$ parameter in the negative binomial distribution was estimated by the maximum likelihood method (Bliss \& Fisher 1953, Ludwig \& Reynolds 1988) and the fit of the negative binomial distribution was tested by the Pearson $\chi^{2}$ statistic (Sokal \& Rohlf 1981).

\section{RESULTS AND DISCUSSION}

C. albiceps larvae attacked C. macellaria larvae during their dispersal process. This result is interesting because no systematic study focusing on the description of larval predation outside the food substrate is available. The impact on C. macellaria was demonstrated by larval recovery. For double species we observed that the mean predation rate by C. albiceps on C. macellaria was $74 \%$, suggesting that larval predation also occurs after the postfeeding period and particularly during larval migration. It is the first time that this kind of behavior is experimentally shown. This result is also relevant because Chrysomya species are implicated in a recent biological invasion process. Four Chrysomya species were introduced to the Americas about 25 years ago and probably displaced the native species C. macellaria (Guimarães et al. 1978, 1979). We strongly believe that the predatory habit of $C$. albiceps had an important impact on the survival rates of C. macellaria.
Most of C. albiceps and C. macellaria larvae were found near the point of larval release (Figs 1-3). For blowfly dispersal experiments, Greenberg (1990) and Godoy et al. (1995) observed similar results. The distribution of larvae differed significantly between species when $C$. albiceps and C. macellaria were released as single species $\left(\mathrm{G}_{\mathrm{H}}=105.92\right.$, first replicate; $\mathrm{G}_{\mathrm{H}}=91.57$, second replicate; $\mathrm{df}=19, \mathrm{P}<0.05)$ (Figs 2, 3). Godoy et al. (1995) and Boldrini et al. (1997) also observed a variation in the dispersal patterns among the blowfly species $C$. megacephala, C. putoria and C. macellaria. They found at least two different distribution patterns in the species studied. The first pattern was defined as a damping oscillation, with bimodal distribution in C. megacephala and C. putoria (Godoy et al. 1995, Boldrini et al. 1997), and the second showed no oscillation and could be defined as a regular diffusion process (Boldrini et al. 1997). In our experiments we found no clear oscillation for $C$. albiceps and C. macellaria and we believe that the oscillation patterns found by Godoy et al. (1995) and Boldrini et al. (1997) do not occur for these species.

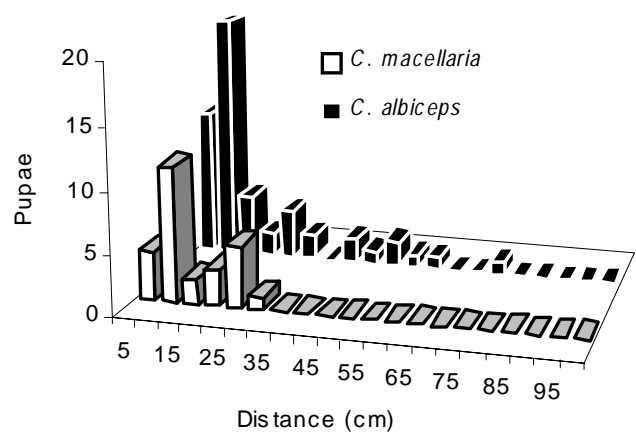

Fig. 1: larval dispersal in Chrysomya albiceps and Cochliomyia macellaria.

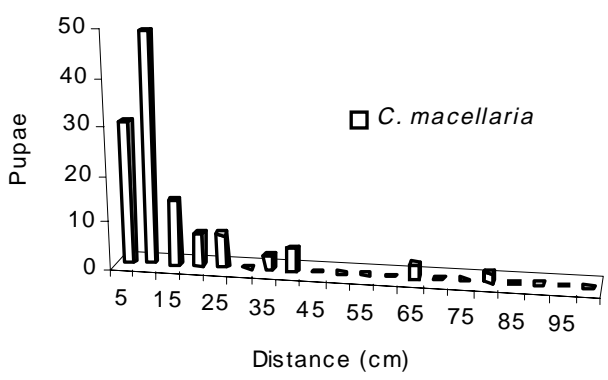

Fig. 2: larval dispersal in Cochliomyia macellaria.

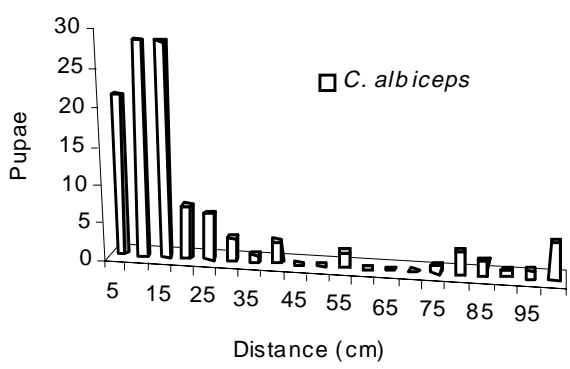

Fig. 3: larval dispersal in Chrysomya albiceps. 
TABLE

Statistical analysis of test (first column) and replicate (second column) of the number of pupae in the 20 sampling units for the two blowfly species: Chrysomya albiceps and Cochliomyia macellaria

\begin{tabular}{|c|c|c|c|c|c|c|c|c|}
\hline \multirow[b]{2}{*}{ Parameters } & \multicolumn{2}{|c|}{ Double species (rep. 1) } & \multicolumn{2}{|c|}{ Double species (rep. 2) } & \multicolumn{2}{|c|}{ Single species (rep. 1) } & \multicolumn{2}{|c|}{ Single species (rep. 2) } \\
\hline & C. albiceps & C. macellaria & C. albiceps & C. macellaria & C. albiceps & C. macellaria & C. albiceps & C. macellaria \\
\hline Mean & 2.65 & 1.3 & 2.6 & 12.3 & 5.74 & 2 & 3.45 & 3.45 \\
\hline Variance & 24.45 & 7.48 & 9.94 & 79.12 & 84.65 & 12.42 & 24.68 & 26.05 \\
\hline $\mathrm{K}$ & 0.49 & 0.16 & 1.26 & 0.83 & 0.55 & 0.16 & 1.73 & 0.21 \\
\hline$\chi^{2}$ & 10.77 & 13.14 & 10.03 & 9.28 & 14.7 & 5.29 & 22.96 & 14.22 \\
\hline d.f. & 13 & 9 & 9 & 14 & 20 & 5 & 10 & 9 \\
\hline
\end{tabular}

When the two species were released together, no significant difference was found regarding frequency distribution $\left(\mathrm{G}_{\mathrm{H}}=10.49\right.$, first replicate; $\mathrm{G}_{\mathrm{H}}=11.53$, second replicate, $\mathrm{df}=19, \mathrm{P}>0.05)$ (Fig. 1). This result suggests some kind of association between the two species. In addition, for double and single experimental settings, both species exhibited an aggregated pattern of distribution since the negative binomial model was fitted to the data (Table). The presence of $C$. albiceps close to $C$. macellaria in order to attack it could explain the similar distribution found. Post-feeding larvae of $C$. albiceps leave the food substrate after consuming the whole food resource. Nevertheless, they may attack $C$. macellaria larvae prior to pupation (Faria et al. 1999).

We used frequency distribution to understand the association between larval predation and aggregation since aggregated distribution has been frequently employed in studies focusing on spatial patterns in the distribution of invertebrates, mainly parasites and insects (Atkinson \& Shorrocks 1984, Shorrocks et al. 1984, Kneidel 1985, Ives 1988, Rosewell et al. 1990, Poulin 1993, Sréter et al. 1994, Umoru 1994).

Observing the mean $k$ values we noticed that $C$. macellaria exhibited higher aggregation level in single than in double species, whereas $C$. albiceps showed higher aggregation level in double than in single species. These results suggest that $C$. macellaria larvae are more aggregated in the absence of $C$. albiceps and, when attacked by $C$. albiceps, their aggregation level decreases because the larvae try to escape or are killed and ingested by $C$. albiceps. In contrast, $C$. albiceps larvae exhibited a smaller aggregation level in absence of C. macellaria, and when searched and caught $C$. macellaria they became more aggregated. This assumption was confirmed by the $G$ test which detected no significant difference between predator and prey distribution for double species. We believe that the results reported here may raise relevant questions about larval predation and dispersal of blowflies.

\section{REFERENCES}

Atkinson WD, Shorrocks B 1984. Aggregation of larval diptera over discrete and ephemeral breeding sites: The implications for coexistence. Am Nat 124: 336-351.

Bliss CI, Fisher RA 1953. Fitting the negative binomial distribution to biological data and a note on the efficient fitting of the negative binomial. Biometrics 9: 176-200.

Boldrini JL, Bassanezi RC, Moretti AC. Zuben FJV, Godoy WAC, Reis SF 1997. Non-local interactions and the dynamics of dispersal in immature insects. J Theor Biol 185: 523-531.

Coe RL 1978. The decomposition of elephant carcases in the Tsavo (East) National, Kenya. J Arid Env 1: 71-86.

Erzinçlioglu YZ, Whitcombe RP 1983. Chrysomya albiceps (Wiedemann) (Dipt., Calliphoridae) in dung and causing myiasis in Oman. Ent Mont Mag 119: 51-52.

Faria LDB, Godoy WAC 2001. Prey choice by facultative predator larvae of Chrysomya albiceps (Diptera:Calliphoridae). Mem Inst Oswaldo Cruz 96: 875-878.

Faria LDB, Orsi L, Trinca LA, Godoy WAC 1999. Larval predation by Chrysomya albiceps on Cochliomyia macellaria, Chrysomya megacephala and Chrysomya putoria. Ent Exp App 90: 149-155.

Fuller ME 1934. The insect inhabitants of carrion, a study animal ecology. Bull Counc Sci Ind Res 82: 5-62.

Gagné RJ 1981. Chrysomya spp., old world blowflies (Diptera, Calliphoridae), recently established in the Americas. Bull Ent Soc Am 27: 21-22.

Godoy WAC, Fowler HG, Von Zuben CJ, Ziti L, Ribeiro OB 1995. Larval dispersion in Chrysomya megacephala, Chrysomya putoria and Cochliomyia macellaria (Diptera: Calliphoridae). J App Ent 119: 263-266.

Godoy WAC, Von Zuben CJ, Reis SF 1996. Larval dispersal in Chrysomya megacephala, Chrysomya putoria and Cochliomyia macellaria (Dipt., Calliphoridae): ecological implications of aggregation behaviour. J App Ent 120: 423426.

Goodbrod JR, Goff ML 1990. Effects of larval population density on rates of development and interactions between two species of Chrysomya (Diptera: Calliphoridae) in laboratory culture. J Med Ent 27: 338-343.

Guimarães JH, Prado AP, Buralli GM 1979. Dispersal and distribution of thre e newly introduced species of Chrysomya Robineau-Desvoidy in Brazil (Diptera, Calliphoridae). Rev Bras Ent 23: 245-255.

Guimarães JH, Prado AP, Linhares AX 1978. Three newly introduced blowfly species in Southern Brazil (Diptera: Calliphoridae). Rev Bras Ent 22: 53-60.

Greenberg B 1990. Behavior of post-feeding larvae of some calliphoridae and a muscid (Diptera). Ann Ent Soc Am 83: 1210-1214.

Hanski I 1977. Biogeography and ecology of carrion flies in the Canary Island. Ann Ent Fenn 43:101-107.

Ives AR 1988. Aggregation and the coexistence of competitors. Ann Zoo Fenn 25: 75-88. 
Kneidel KA 1985. Patchiness, aggregation and the coexistence of competitors for ephemeral resources. Ecol Ent 10: 441448.

Legner EF 1977. Temperature, humidity and depth of habitat influencing host destruction and fecundity of muscoid fly parasites. Entomophaga 22: 199-206.

Levot GW, Brown KR, Shipp E 1979. Larval growth of some calliphorid and sarcophagid Diptera. Bull Ent Res 69: 469475.

Ludwig JA, Reynolds JF 1988. Statistical Ecology, a Primer on Methods and Computing, John Wiley \& Sons, New York, $337 \mathrm{pp}$.

Peschke K, Krapp D, Fuldner D 1987. Ecological separation, functional relationships, and limiting resources in a carrion insect community. Zool Jahrb Syst 114: 241-265.

Poulin R 1993. The disparity between observed and uniform distribution: a new look at parasite aggregation. Int J Par 23: 937-944.

Putman RJ 1977. Dynamics of the blowfly, Calliphora erythrocephala, within carrion. J Anim Ecol 46: 853-866.

Reis SF, Zuben CJV, Godoy WAC 1999. Larval aggregation and competition for food in experimental populations of Chrysomya putoria (wied.) and Cochliomyia macellaria (f.) (Dipt. Calliphoridae). J App Ent 123: 485-489.

Rosewell B, Shorrocks B, Edwards K 1990. Competition on a divided ephemeral resources: testing the assumptions. I. Aggregation. J Anim Ecol 59: 977-1001.

Sokal RR, Rohlf FJ 1981. Biometry, Freeman and Company, New York, 859 pp.

Shorrocks B, Rosewell J, Edwards K, Atkinson WD 1984. Interspecific competition is not a major organism force in many insect communities. Nature 310: 310-312.

Srétter T, Molnár V, Kassai T 1994. Distribution of nematode egg counts and larval count in grazzing sheep and their implications for parasites control. Int J Par 24: 103-108.

Umoru PA 1994. Aggregation of frit fly larvae (Oscinella spp.; Geomyza tripunctata Fall.) and immature hymenopterous parasitoids in grassland in northern England. J App Ent 117: 158-164.

Wells JD, Greenberg B 1992a. Rates of predation by Chrysomya rufifacies (Macquart) on Cochliomyia macellaria (Fabr.) (Diptera: Calliphoridae) in the laboratory: effect of predator and prey development. Pan-Pac Ent 68: 12-14.

Wells JD, Greenberg B 1992b. Laboratory interaction between introduced Chrysomya rufifacies and native Cochliomyia macellaria (Diptera: Calliphoridae). Env Ent 21: 640-645.

Wells JD, Greenberg B 1992c. Interaction between Chrysomya rufifacies and Cochliomyia macellaria (Diptera: Calliphoridae): the possible consequences of an invasion. Bull Ent Res 82: 133-137. 